Available online at: http://journal.unj.ac.id

Jurnal

Pensil

Pendidikan Teknik Sipil

Journal homepage: http://journal.unj.ac.id/unj/index.php/jpensil/index

\title{
PEMANFAATAN LIMBAH KARBIT SEBAGAI BAHAN TAMBAH PADA MORTAR DITINJAU DARI KUAT TEKAN
}

\section{UTILIZATION OF WASTE CARBITE AS ADDITIONAL MATERIAL IN MORTAR VIEWING FROM COMPRESSIVE STRENGTH}

\author{
Wisnu Adhi Saputra ${ }^{1}$, Anisah', Rosmawita Saleh ${ }^{3}$ \\ Universitas Negeri Jakarta, JL. Rawamangun Muka, Jakarta Timur, 13122, Indonesia \\ 1.wisnuadhisaputra1@gmail.com ${ }^{2}$ anisah_mt@unj.ac.id ${ }^{3}$ rosmawitasaleh@unj.ac.id
}

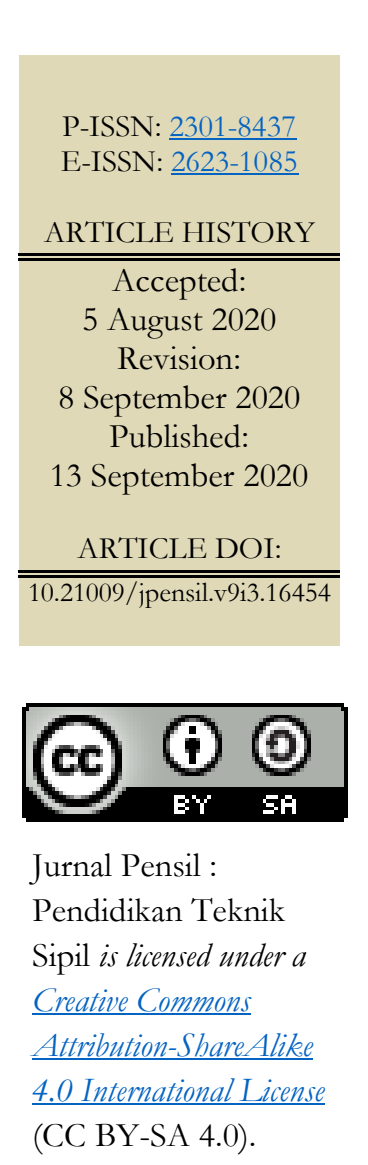

Pembangunan infrastruktur yang terjadi menyebabkan penggunaan semen meningkat setiap tahunnya. Untuk mengurangi produksi semen diperlukan alternatif pengganti lain, salah satu bahan alternatif yang dapat dimanfaatkan adalah limbah karbit. Pemanfaatan limbah karbit jika ditambahkan sebagai bahan perlu ditangani terlebih dahulu sebelum digunakan. Penambahan limbah karbit sebagai bahan campuran mortar diharapkan dapat memberikan reaksi pozolanik sehingga akan meningkatkan kuat tekan mortar. Penelitian ini bertujuan untuk membuktikan apakah limbah karbit sebagai bahan tambah dapat mencapai kuat tekan mortar tipe M berdasarkan SNI 6882-2014. Penelitian ini menggunakan metode eksperimen dengan total 36 benda uji kubus berukuran $50 \mathrm{~mm}$ tiap sisinya, faktor air semen 0,4 kuat tekan rencana tipe $\mathrm{M}(17,2 \mathrm{MPa})$. Benda uji berupa mortar dengan penambahan bahan limbah karbit dengan variasi $0 \%, 2,5 \%, 5 \%, 7,5 \%$, $10 \%$, dan $12,5 \%$ berat semen. Hasil penelitian menunjukkan bahwa semua variasi dengan penambahan limbah karbit dapat meningkatkan kuat tekan melebihi mutu tipe $\mathrm{M}(17,2 \mathrm{MPa})$. Kuat tekan rata-rata mortar dengan variasi penambahan limbah karbit $0 \%, 2,5 \%, 5 \%, 7,5 \%$, $10 \%$, dan $12,5 \%$ dari berat semen pada umur 28 hari berturut-turut sebagai berikut adalah 20, $67 \mathrm{MPa}, 23,33 \mathrm{MPa}, 22 \mathrm{MPa}, 26,67 \mathrm{MPa}$, 24,33 MPa, $19 \mathrm{MPa}$. Kuat tekan maksimum terjadi pada variasi limbah karbit $7,5 \%$

Kata kunci: Kuat Tekan, Limbah Karbit, Pozolan

\begin{abstract}
Infrastructure development that occurs causes cement demand to increase each year To reduce cement production, other alternative substitutes are needed, one alternative material that can be utilized is carbide waste. Utilization of carbide waste if added as material needs to be handled first before use. The addition of carbide waste as an ingredient in mixing mortar is expected to give a pozolanic reaction so that it will increase the compressive strength of the mortar. The aim of this research is to prove whether carbide waste as an added material can reach the $M$ type mortar
\end{abstract}


compressive strength based on SNI 6882-2014. This study used an experimental method with a total of 36 cube specimens measuring $50 \mathrm{~mm}$ each side, a cement water factor of 0.4, the compressive strength of an M-type plan (17.2 MPa). The specimens consisted of mortars with added carbide waste materials with variations of $0 \%, 2.5 \%, 5 \%, 7.5 \%, 10 \%$, and $12.5 \%$ by weight of cement. The results showed that all variations with the addition of carbide waste can increase the compressive strength to exceed the quality of type $M$ quality (17.2 MPa). Average compressive strength of mortar with the addition of carbide waste variations of $0 \%, 2.5 \%, 5 \%$, $7.5 \%, 10 \%$, and $12.5 \%$ of the weight of cement at 28 days respectively as follows are 20, 67 MPa, 23.33 MPa, $22 \mathrm{MPa}, 26.67 \mathrm{MPa}$, 24.33 MPa, $19 \mathrm{MPa}$. Maximum compressive strength occurs at a variation of $7.5 \%$ carbide waste

Keywords: Compressive Strength, Carbide Waste, Pozolan

\section{Pendahuluan}

Pembangunan infrastruktur yang besar telah terjadi diberbagai wilayah Indonesia yang menyebabkan konsumsi semen dalam negeri meningkat sebesar $3,6 \%$ yang mana 30.047 .831 ton pada tahun 2018 dan pada tahun 2017 sebanyak 28.994.253 ton (Administrator, 2018). Menurut Atmaja, dalam periode 2012 pabrik semen di Pulau Jawa memberikan kontribusi emisi karbon diosksida sebesar 26.921.591 ton dari total 35.500.000 ton semen yang di produksi atau rata-rata 0,77 ton $\mathrm{CO} 2$ per ton semen yang diproduksi. Artinya dari produksi semen tahun 2015 telah menghasilkan emisi karbon dioksida sebesar 57.976.380 ton (Atmaja, 2015). Salah satu solusi untuk mengatasi ini adalah menemukan bahan alternatif lain yang memiliki sifat seperti semen contohnya adalah limbah karbit yang memiliki kandungan $\mathrm{CaO}$ yang tinggi seperti semen. Senyawa $\mathrm{CaO}$ dalam semen berfungsi sebagai pengontrol kekuatan dan ketahanan material terhadapa pelapukan $\mathrm{SiO} 2$ sebagai penambah kekuatan, jika terlalu banyak akan membuat (setting time) lambat (Sagel dkk, 1997 dalam Perdana,N.S dkk, 2018). Limbah karbit merupakan hasil reaksi antara kalsium karbida (CaC2) dengan air $\mathrm{H} 2 \mathrm{O}$ untuk menghasilkan gas acetylene (C2H2) dan calcium hydroxide $\mathrm{Ca}(\mathrm{OH}) 2$ (Dewi, N.R dkk, 2016)
Pada penelitian ini limbah karbit digunakan sebagai bahan tambah dan untuk mengurangi bau menghilangkan kotoran yang terdapat pada limbah karbit maka, limbah karbbit direndam terlebih dahulu dengan air selama 7 hari untuk mengurangi bau menyengat yang terdapat pada limbah karbit serta untuk menghilangkan kotoran yang lainya kemudian keringkan selama 2 hari dibawah sinar matahari dan haluskan agar gradasi sama. Pada pengujian kuat tekan mortar dengan penggunaan limbah karbit sebagai bahan tambah mortar dengan campuran mortar 1 semen : 2 pasir dengan faktor air semen (fas) 0,4, yang bertujuan agar menghasilkan mortar tipe $\mathrm{M}$ sebesar 17,2 $\mathrm{MPa}$ pada usia 28 hari dengan variasi campuran bahan tambah limbah karbit sebesar $0 \%, 2,5 \%, 5 \%, 7,5 \%, 10 \%$ dan $12,5 \%$ dari berat semen.

\section{Metode Penelitian}

Metode penelitian yang digunakan adalah metode eksperimen dengan menggunakan mortar 7 dan 28 hari dengan penambahan limbah karbit sebesar $0 \%$, $2,5 \%, 5 \%, 7,5 \%, 10 \%$, dan $12,5 \%$ dari berat semen yang digunakan. Penelitian ini dilakukan di Laboratoriun Bahan Fakultas Teknik Universitas Negeri Jakarta pada bulan September 2019 yang bertujuan untuk membuktikan apakah mortar dengan bahan tambah limbah karbit dapat menaikan nilai 
kuat tekan mortar mencapai mutu mortar tipe-M sebesar 17,2 MPa. Campuran mortar yang digunakan adalah 1 semen : 2 pasir : limbah karbit $(0 \%, 2,5 \%, 5 \%, 7,5 \%, 10 \%$, $12,5 \%$ ) berjumlah total 36 benda uji dengan masing- masing setiap variasi 3 benda uji.

\section{Hasil Penelitian dan Pembahasan}

Uji Konsistensi Mortar

Hasil nilai konsistensi dapat dilihat pada Tabel 1 dan Gambar 1.

Tabel 1. Hasil Uji Slump

\begin{tabular}{c|c}
\hline $\begin{array}{c}\text { Presentase Agregat } \\
\text { Limbah Karbit }\end{array}$ & $\begin{array}{c}\text { Nilai Konsistensi } \\
\mathbf{( \% )}\end{array}$ \\
\hline $0 \%$ & $112,5 \%$ \\
\hline $2,5 \%$ & $105 \%$ \\
\hline $5,0 \%$ & $112,5 \%$ \\
\hline $7,5 \%$ & $117,5 \%$ \\
\hline $10,0 \%$ & $107,5 \%$ \\
$12,5 \%$ & $112,5 \%$ \\
\hline
\end{tabular}

Pengujian nilai konsistensi dilakukan untuk mengetahui nilai konsistensi semen yang terdapat pada semen sehingga semua butiran semen dapat terhidrasi dan kekuatan pasta semen tidak turun. Nilai konsistensi mortar dengan penambahan limbah karbit sebesar $0 \%, 2,5 \%, 5 \%, 7,5 \%, 10 \%$, dan
$12,5 \%$ secara berturut-turut yaitu $112,5 \%$, $112 \%, \quad 112,5 \%, \quad 117,5 \%, \quad 107,5 \%$ dan $112,5 \%$, dengan nilai faktor air semen 0,4. Dari hasil pengujian konsistensi dapat disimpulkan bahwa nilai konsistensi mortar paling tinggi sebesar $117,5 \%$ pada variasi limbah karbit 7,5\% dari berat semen. Hal ini menyebabkan adukan mortar tersebut melewati batasan untuk nilai flow kelecakan mortar maksimum sebesar $115 \%$, sehingga adukan menjadi lebih cair dibandingkan dengan adukan dengan vaariasi limbah karbit yang lainnya.

Uji Berat Isi

Hasil berat isi dapat dilihat pada Tabel 2 dan Gambar 2.

Tabel 2. Hasil Berat Isi

\begin{tabular}{c|c|c}
\hline $\begin{array}{c}\text { Presentase } \\
\text { Limbah } \\
\text { Karbit }\end{array}$ & $\begin{array}{c}\text { Berat } \\
\text { Mortar 7 } \\
\text { Hari Rata- } \\
\text { Rata (gram) }\end{array}$ & $\begin{array}{c}\text { Berat } \\
\text { Mortar 28 } \\
\text { Hari Rata- } \\
\text { Rata } \\
\text { (gram) }\end{array}$ \\
\hline $0 \%$ & 278,73 & 262,70 \\
\hline $2,5 \%$ & 280,27 & 266,83 \\
\hline $5,0 \%$ & 283,00 & 267,87 \\
\hline $7,5 \%$ & 277,47 & 277,70 \\
\hline $10,0 \%$ & 271,80 & 275,90 \\
$12,5 \%$ & 269,70 & 277,50 \\
\hline
\end{tabular}

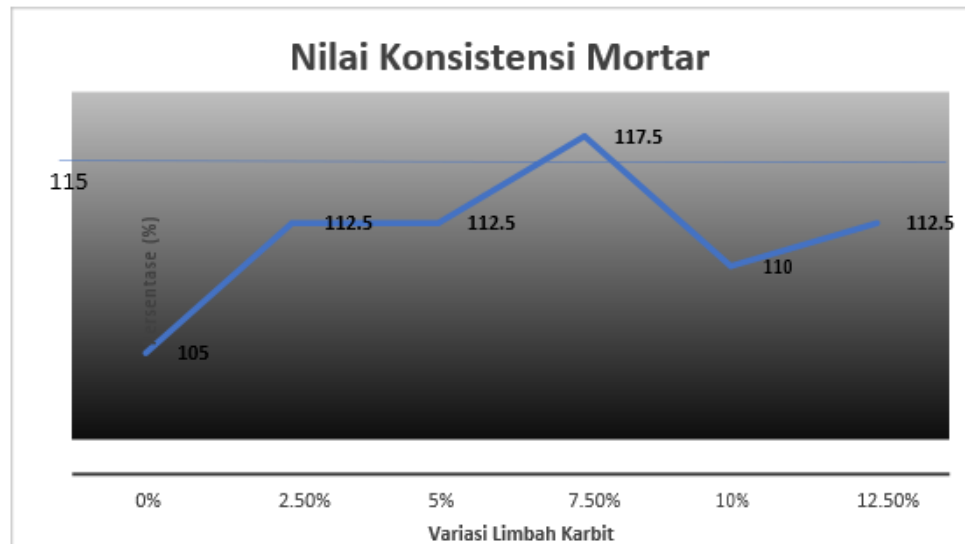

Gambar 1. Grafik Nilai Uji Konsistensi 


\section{BERAT ISI MORTAR}

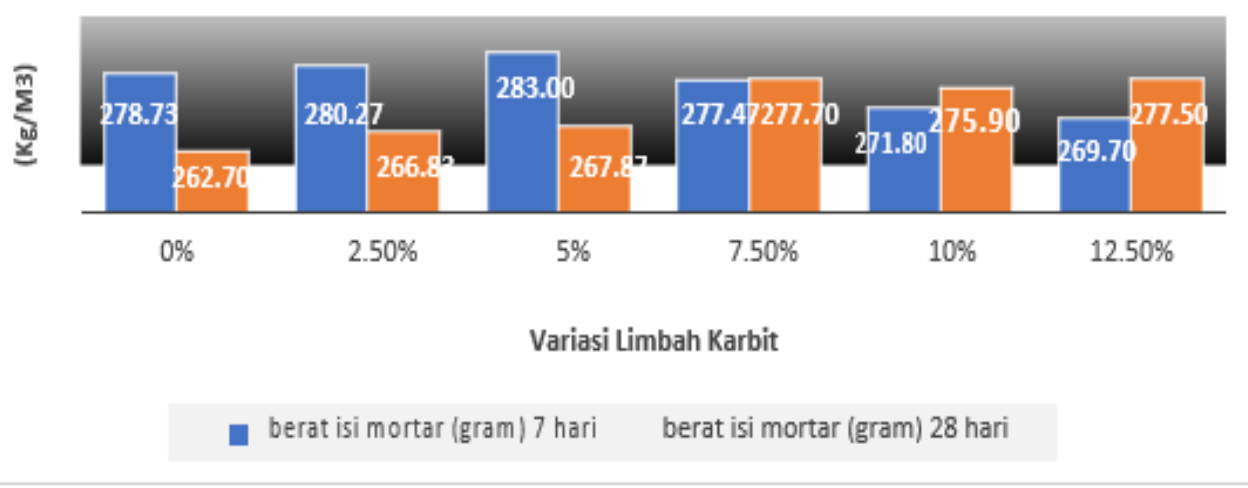

Gambar 2. Grafik Batang Berat Isi Beton

\section{PENYERAPAN AIR MORTAR}

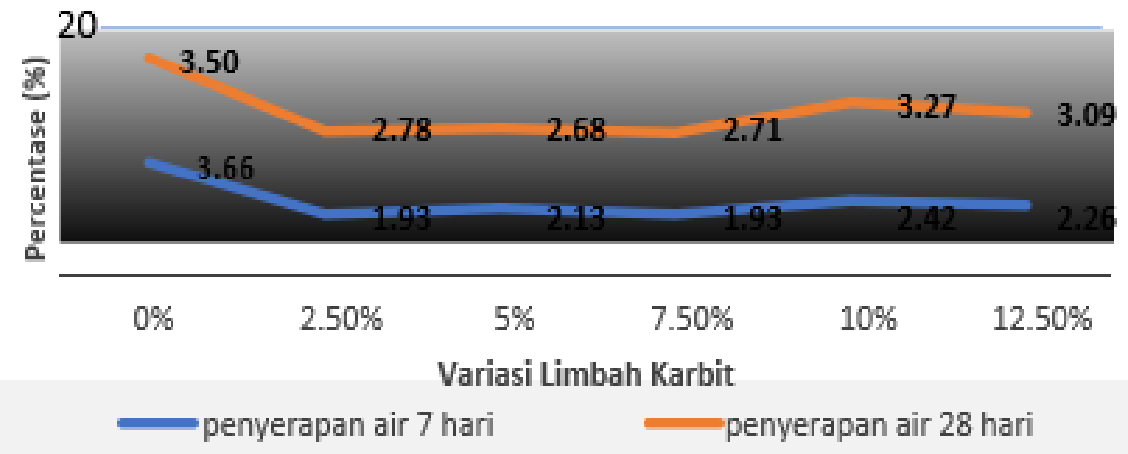

Gambar 3. Grafik Penyerapan Air Pada Mortar

Pengujian berat isi dilakukan untuk mengetahui berat isi dari mortar yang akan di uji. Dari hasil pengujian berat isi ini dapat disimpulkan bahwa nilai berat isi terbesar pada usia 7 hari pada variasi 5\% penambahan limbah karbit sebesar 283 gram sedangkan untuk berat isi terbesar pada usia 28 hari pada variasi $7,5 \%$ penambahan limbah karbit sebesar 277,70 gram.

Uji Penyerapan Air Mortar

Hasil nilai penyerapan air pada mortar dapat dilihat pada Tabel 3, Tabel 4 dan Gambar 3.
Tabel 3. Hasil Uji Penyerapan Air

\begin{tabular}{c|c}
\hline $\begin{array}{c}\text { Presentase Agregat } \\
\text { Limbah Karbit }\end{array}$ & $\begin{array}{c}\text { Nilai Penyerapan } \\
\text { Air 7 Hari (\%) }\end{array}$ \\
\hline $0 \%$ & $3.66 \%$ \\
\hline $2,5 \%$ & $1.93 \%$ \\
\hline $5,0 \%$ & $2.13 \%$ \\
\hline $7,5 \%$ & $1.93 \%$ \\
\hline $10,0 \%$ & $2.42 \%$ \\
$12,5 \%$ & $2.26 \%$ \\
\hline
\end{tabular}

Tabel 4. Hasil Uji Penyerapan Air

\begin{tabular}{c|c}
\hline $\begin{array}{c}\text { Presentase Agregat } \\
\text { Limbah Karbit }\end{array}$ & $\begin{array}{c}\text { Nilai Penyerapan } \\
\text { Air 28 Hari (\%) }\end{array}$ \\
\hline $0 \%$ & $3.50 \%$ \\
\hline $2,5 \%$ & $2.78 \%$ \\
\hline $5,0 \%$ & $2.68 \%$ \\
\hline $7,5 \%$ & $2.71 \%$ \\
\hline $10,0 \%$ & $3.27 \%$ \\
$12,5 \%$ & $3.09 \%$ \\
\hline
\end{tabular}


Pengujian penyerapan air pada mortar dilakukan melalui perbandingan benda uji dalam keadaan kering dengan keadaan jenuh air. Pada pengujian penyerapan air hal yang harus diperhatikan adalah berat sebelum dilakukan perendaman dan setelah perendaman. Dari hasil penyerapan air pada mortar ini dapat disimpulkan bahwa penyerapan air yang terjadi pada benda uji mortar mengalami penurunan dibandingkan dengan mortar normal akan tetapi semua benda uji dengan variasi penambahan limbah karbit tidak melewati nilai penyerapan $20 \%$, sehingga benda uji telah memenuhi persyaratan SNI 15-2094-2000 tentang penyerapan air mortar.

\section{Uji Kuat Tekan}

Hasil kuat tekan mortar 7 hari dapat dilihat pada Tabel 5 dan Gambar 4.

Tabel 5. Hasil Kuat Tekan Mortar 7 Hari

\begin{tabular}{c|c}
\hline $\begin{array}{c}\text { Presentase Agregat } \\
\text { Limbah Karbit }\end{array}$ & $\begin{array}{c}\text { Kuat Tekan Mortar } \\
\text { Rata-Rata (MPa) }\end{array}$ \\
\hline $0 \%$ & 15,00 \\
\hline $2,5 \%$ & 18,00 \\
\hline $5,0 \%$ & 23,00 \\
\hline $7,5 \%$ & 20,33 \\
\hline $10,0 \%$ & 19,00 \\
$12,5 \%$ & 16,00 \\
\hline
\end{tabular}

Berdasarkan diagram Gambar 4, pada persentase normal $0 \%$ didapatkan nilai kuat tekan sebesar $15 \mathrm{MPa}$. Pada penambahan $2,5 \%$ limbah karbit mengalami kenaikan sebesar $18 \mathrm{MPa}$ dengan persentase $20 \%$ jika dibandingkan mortar normal. Pada penambahan $5 \%$ limbah karbit mengalami kenaikan sebesar $23 \mathrm{MPa}$ dengan persentase kenaikan $66,67 \%$ jika dibandingkan mortar normal, sedangkan pada variasi 7,5\% limbah karbit mengalami penurunan dengan nilai kuat tekan sebesar 20,33 $\mathrm{MPa}$ jika dibandingkan mortar dengan penambahan 5\% limbah karbit, namun mengalami kenaikan nilai kuat tekan dibandingkan mortar normal dengan persentase sebesar 35,53\%.

Hasil kuat tekan mortar 28 hari dapat dilihat pada Tabel 6 dan Gambar 5.

Tabel 6. Hasil Kuat Tekan Mortar 28 Hari

\begin{tabular}{c|c}
\hline $\begin{array}{c}\text { Presentase } \\
\text { Agregat Limbah } \\
\text { Karbit }\end{array}$ & $\begin{array}{c}\text { Kuat Tekan Mortar } \\
\text { Rata-Rata (MPa) }\end{array}$ \\
\hline $0 \%$ & 20,67 \\
\hline $2,5 \%$ & 23,33 \\
\hline $5,0 \%$ & 22,00 \\
\hline $7,5 \%$ & 26,67 \\
\hline $10,0 \%$ & 24,33 \\
$12,5 \%$ & 19,00 \\
\hline
\end{tabular}

Berdasarkan diagram Gambar 5, pada persentase normal $0 \%$ didapatkan nilai kuat tekan sebesar 20,67 MPa. Pada penambahan 2,5\% limbah karbit mengalami kenaikan sebesar $23,33 \mathrm{MPa}$ dengan persentase $12,87 \%$ jika dibandingkan mortar normal, sedangkan pada variasi 5\% limbah karbit mengalami penurunan dengan nilai kuat tekan sebesar $22 \mathrm{MPa}$ jika dibandingkan mortar dengan penambahan 2,5\% limbah karbit, namun mengalami kenaikan nilai kuat tekan dibandingkan mortar normal dengan persentase sebesar $6,43 \%$. Pada penambahan $7,5 \%$ mengalami kenaikan sebesar 26,67\% jika dibandingkan mortar dengan penambahan $5 \%$ limbah karbit, sehingga nilai kuat tekan jika dibandingkan mortar normal mengalami kenaikan dengan persentase 29,03\%. Pada penambahan $10 \%$ limbah karbit mengalami penurunan dengan nilai kuat tekan 24,33 $\mathrm{MPa}$ jika dibandingkan mortar dengan penambahan 7,5\% limbah karbit, namun mengalami kenaikan nilai kuat tekan dibandingkan mortar normal dengan persentase $17,7 \%$. Pada penambahan $12,5 \%$ limbah karbit mengalami penurunan dengan nlai kuat tekan $19 \mathrm{MPa}$.

Pada mortar usia 7 hari kuat tekan optimum berada pada variasi 5\% limbah karbit sebesar $23 \mathrm{MPa}$, akan tetapi pada 
usia 28 hari kuat tekan optimum berada pada variasi $7,5 \%$ limbah karbit sebesar 26,67 MPa. Hal ini disebabkan karena mortar 5\% limbah karbit pada usia 28 hari mengalami kecacatan berupa terdapatnya beberapa lubang-lubang kecil, sehingga hal tersebut diduga menyebabkan penurunan kuat tekan yang terjadi pada benda uji tersebut seperti Gambar 6 berikut.

kuat tekan 7 hari

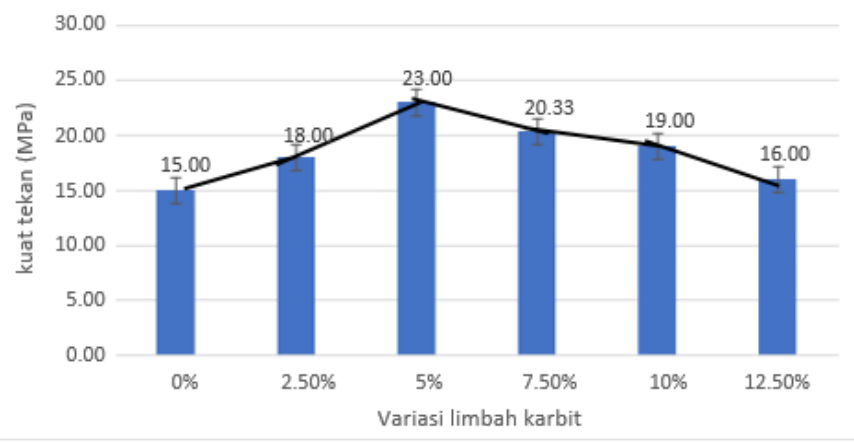

Gambar 4. Grafik Kuat Tekan Mortar 7 Hari

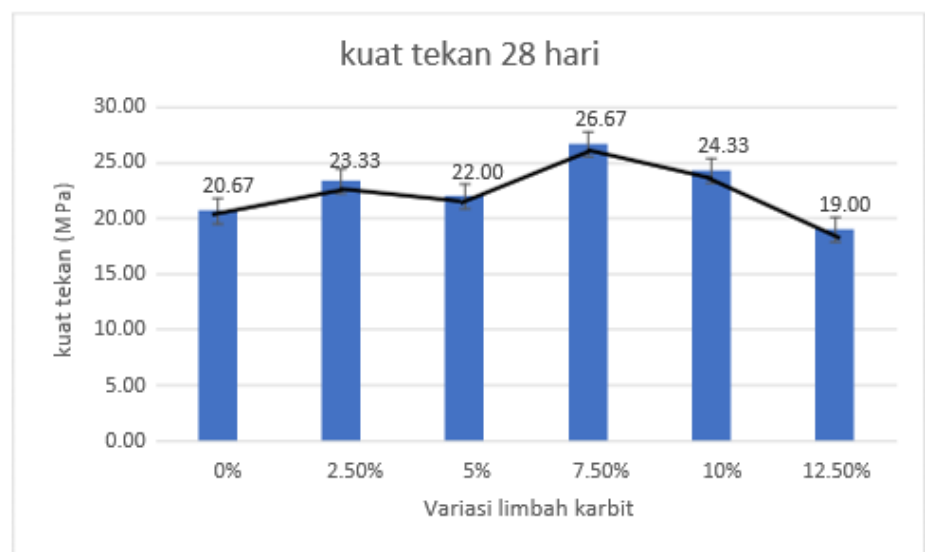

Gambar 5. Grafik Kuat Tekan Mortar 28 Hari

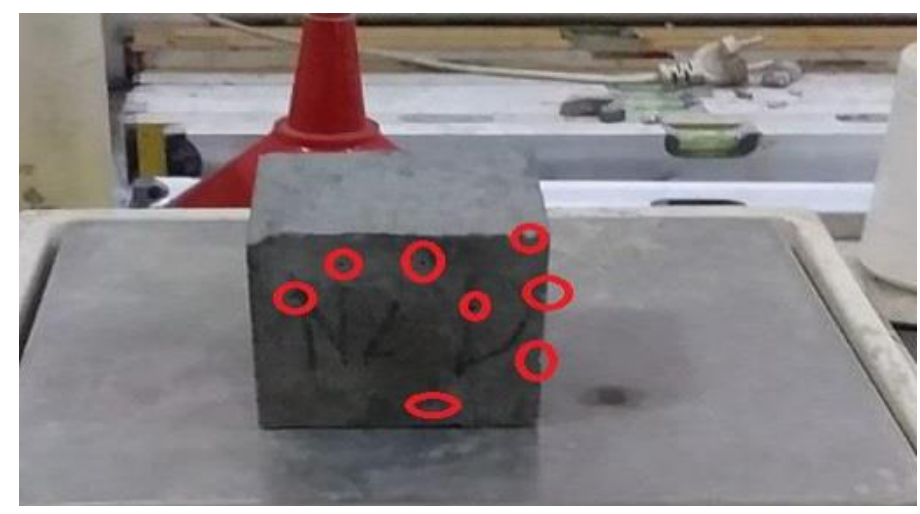

Gambar 6. Contoh Benda Uji Cacat Berlubang 


\section{Simpulan}

Pemanfaatan limbah karbit sebagai bahan tambah ditinjau dari kuat tekan dapat mencapai kuat tekan mortar tipe $M$, sehingga dari penelitian ini dapat disimpulkan sebagai berikut: Pertama, penggunaan limbah karbit sebagai bahan tambah mortar untuk kuat tekan dapat meminimalisir limbah karbit yang terbuang dan tak terpakai pada beberapa tempat pengisian gas acetylene yang digunakan untuk pengelasan. Kedua, ortar dengan penambahan limbah karbit dengan variasi $0 \%, 2,5 \%, 5 \%, 7,5 \%, 10 \%$ dan $12,5 \%$ dapat meningkatkan kuat tekan mortar pada pencampuran 1 Pasir: 2 Semen yang melebihi mutu mortar tipe M yaitu 17,2 $\mathrm{MPa}$ yang dapat digunakan sebagai dinding penahan. Ketiga, pencampuran limbah karbit paling optimum terdapat pada variasi $7,5 \%$ yang memiliki nilai konsistensi tertinggi dan semua variasi penambahan limbah karbit memiliki nilai penyerapan air pada mortar kurang dari $20 \%$ sesuai dengan syarat SNI 15-2094-2000 tentang penyerapan air mortar.

\section{Daftar Pustaka}

Administrator, (2018) .Cement Industry in Indonesia. [Online] Available at: https://asi.or.id/2019/06/Cement-
Industry-in-indonesia/ [Accessed 28 November 2018].

Atmaja, (2015). Industri Semen Dan Emisi Carbon Dioxide di Pulan Jawa

Badan Standarisasi Nasional, (2014). Spesifikasi Mortar Untuk Pekerjaan Unit Pasangan. In: SNI 03-6882-2014. Jakarta: s.n

Dewi, N.R, Dermawan, D.,\& Ashari, M.L, (2016). Studi Pemanfaatan Limbah Karbit B3dan Fly Ash Sebagai Bahan Campuran Beton SIap Pakai (BSP) (Studi kasus:PT. Varia Usaha Beton). In: Jurnal Presipitasi

Pemerintah Republik Indonesia, (2014) . PP No 101 tahun 2014. In: pemanfaatan limbah beracun (B3). Indonesia: Pemerintah Republik Indonesia, p. Nomor $22 \mathrm{BAB} 1$.

Perdana N.S, dkk, (2018). Identifikasi Komposisi Limbah Karbit dan Pengarub Penambahan Limbah Karbit Terbadap Uji Waktu Ikat Semen (Uji Setting Time). Jurnal PPNS 